\title{
A New Efficient Photoiniferter for Living Radical Photopolymerization.
}

\author{
J. Lalevée*, X. Allonas, J.P. Fouassier \\ Department of photochemistry, Ecole Nationale Supérieure de Chimie de Mulhouse, 3 rue \\ Alfred Werner, 68093 Mulhouse Cedex - France. \\ e-mail: j.lalevee@uha.fr
}

CORRESPONDING AUTHOR : Jacques Lalevée.

e-mail: j.lalevee@uha.fr, Tel : 33 (0)389336837, Fax : 33 (0)389336895.

\section{Supporting Information :}

\section{List of contents :}

Figure 1. Polymerization kinetics of HDDA film $(50 \mu \mathrm{m})$ in the presence of 2,2-dimethoxy-2phenylacetophenone (DMPA); $\boldsymbol{I} ; \boldsymbol{I I} ; \boldsymbol{I I I}$ or $\boldsymbol{I} \boldsymbol{V}$. Insert : excitation lamp spectrum.

Figure 2. Decay of the dimethyldithiocarbamyl radicals observed at $600 \mathrm{~nm}$ by LFP for I (a) and II (b) in acetonitrile.

Figure 3. Plot of Rp vs 1/[IV]. 
Figure 1.

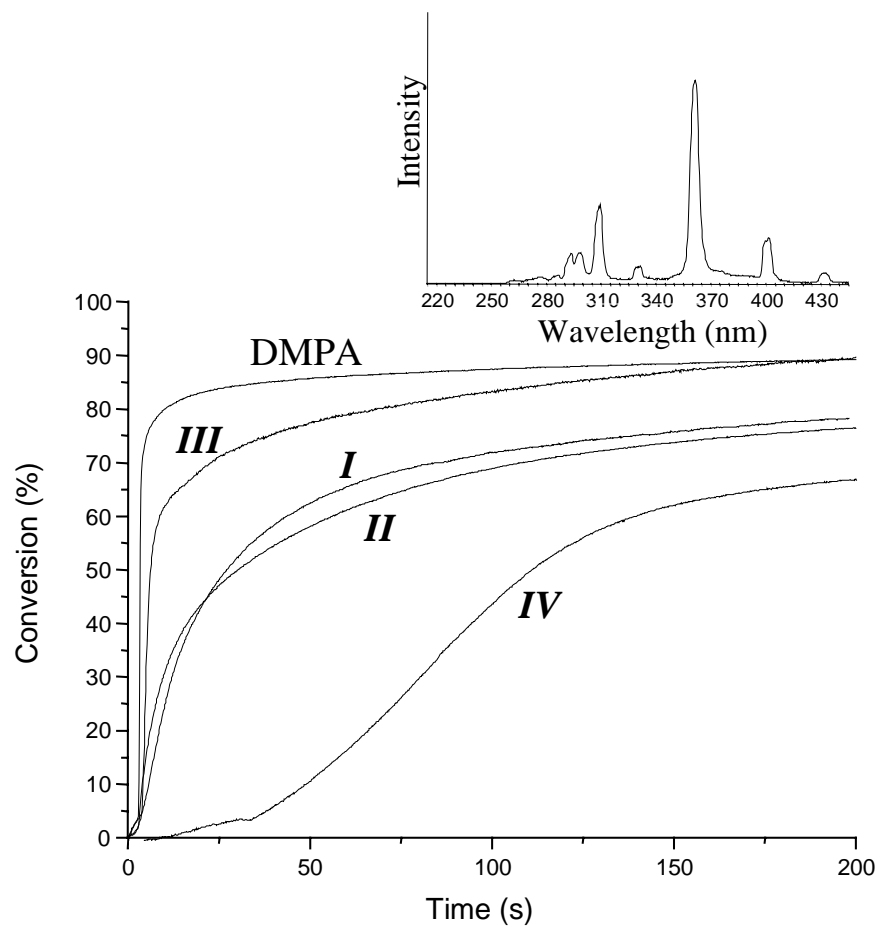


Figure 2.

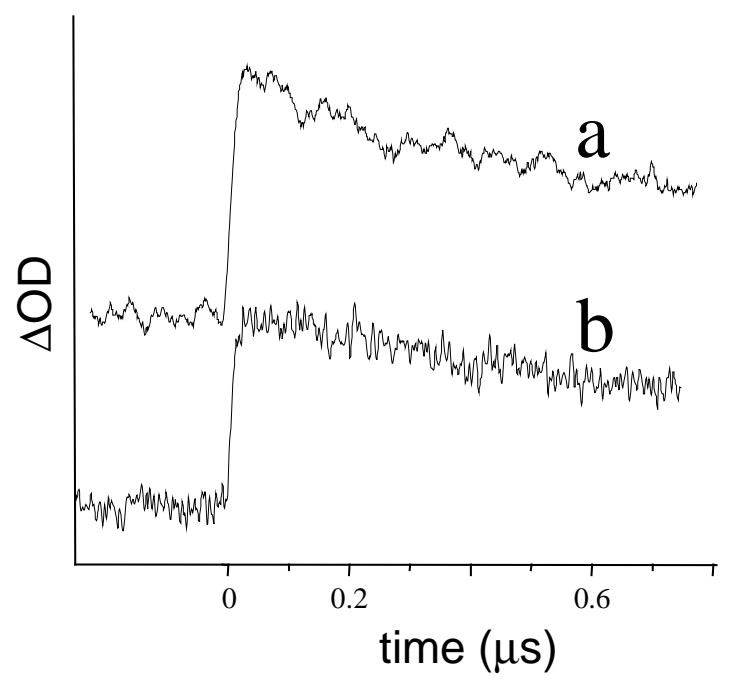


Figure 3.

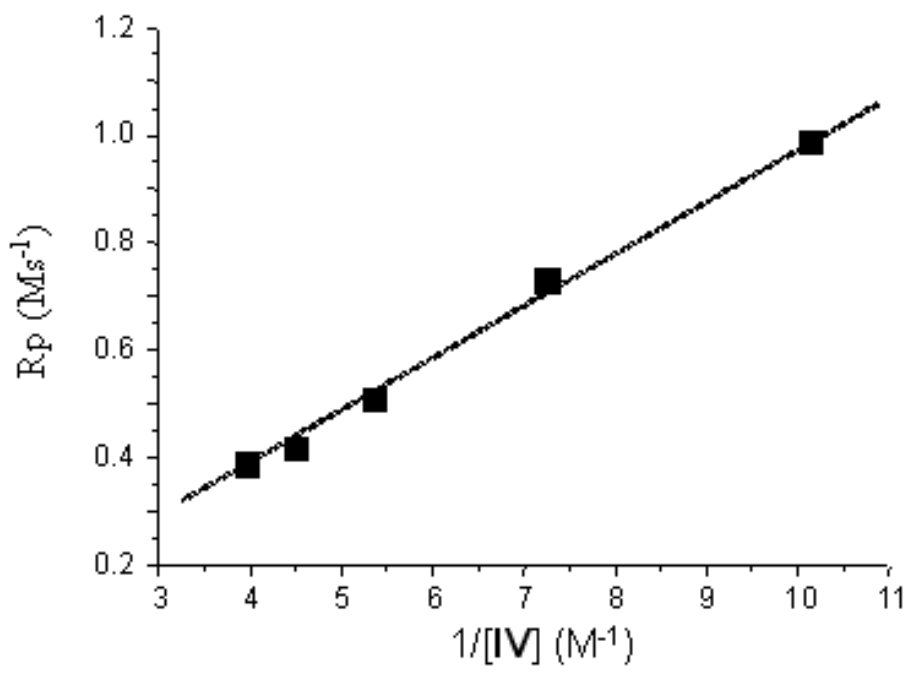




\section{Copolymer synthesis:}

Using I, the formation of a MMA-Styrene copolymer through a sequential approach is achieved.

The photoiniferter I (1\%) and the first monomer (methyl methacrylate-MMA) were irradiated in a quartz flask with the Xe- Hg lamp. The monomer excess was removed under vacuum; $30 \%$ of MMA are incorporated after about $15 \mathrm{mn}$ of irradiation: this result demonstrates that I can be used for the synthesis of the PMMA photoiniferter A second monomer (styrene - St) is added and the photopolymerization restarted : after $1000 \mathrm{~s}$ of UVirradiation, $40 \%$ of styrene was polymerized, thereby leading to a PMMA-PS copolymer. Other copolymers can be probably formed using the low selectivity property of $\mathrm{TZ}^{*}$ towards monomers (mentioned above). The insertion of dormant species $\left(\mathrm{R}-\mathrm{M}_{\mathrm{n}}-\mathrm{DC}\right)$ in a polymer

matrix is worthwhile for many applications as recently reported. ${ }^{3-4}$ The synthesis of copolymers with I demonstrates the potential of this structure for practical applications. 